\title{
El Análisis Político del Discurso: Diálogo entre Ciencias del Lenguaje y Ciencia Política'
}

\author{
Political Discourse Analysis: Dialogue between \\ Language Sciences and Political Sciences
}

\author{
José Ignacio Correa Medina ${ }^{2}$ \\ Cecilia Dimaté Rodríguez ${ }^{3}$
}

Resumen

En el Análisis Político del Discurso confluyen elementos conceptuales de múltiples procedencias, puestos en diálogo con la vida política cotidiana, en la dirección de alcanzar cotas más altas en la comprensión de las problemáticas del ejercicio del poder y de la vida en comunidad. El presente trabajo inicia un acercamiento a dos casos de la vida colombiana, a la luz de estos presupuestos teóricos.

\section{Palabras clave:}

Discurso, política, ideología, antagonismo, hegemonía.

\section{Abstract}

In the Political Discourse Analysis, multiple conceptual elements from different sources come together and are put in interaction with everyday political life. This is done in order to have a deeper and comprehensive understanding of the problems that come with the exercise of power and life in a community. This paper presents an initial analysis of two Colombian everyday political life, base on the theoretical principles.

Keywords:

Discourse, politics, ideology, antagonism, hegemony

Artículo recibido el 31 de enero de 2011 y aprobado el 28 de marzo de 2011

1 Este artículo surge de la relación dialógica entre los proyectos de investigación que, acerca de los movimientos sociales y de la formación política en el sistema educativo colombiano, vienen desarrollando los autores en el marco del Doctorado en Estudios Políticos de la Universidad Externado de Colombia. Asimismo, el artículo recoge algunos de los planteamientos y debates de los autores en ese marco y en eventos académicos tales como el VI Congreso Nacional de Estudios del Discurso, Colombia, 2010, y el 21er. Congreso Mundial de Ciencia Política, Chile, 2009.

2 Profesor Departamento de Lenguas, Universidad Pedagógica Nacional. Grupo de investigación GIPELEC. jicorrea@pedagogica.edu.co

3 Profesora Departamento de Lenguas, Universidad Pedagógica Nacional. Grupo de investigación GIPELEC. cdimate@pedagogica.edu.co 


\section{Palabras previas}

Los innegables avances en la praxis del análisis del discurso, nos ofrecen alternativas que van desde un acercamiento puramente ingenuo ${ }^{4}$ a uno que resulta altamente especializado en diferentes órdenes: lingüístico-gramatical, semiótico, discursivo, sociológico, político, etc. No obstante, la relación entre análisis del discurso y ciencia política estuvo signada, hasta bien entrado el siglo XX, por una serie de análisis de tipo estructural, con una metodología de corte intuitivo que, en no pocas ocasiones, constituye productos con explícitos sesgos gramaticales o con una pretendida neutralidad cuya validez ha sido cuestionada desde múltiples sectores teóricos, políticos e ideológicos ${ }^{5}$. Por otra parte, a pesar de los desarrollos de una propuesta analítica como la de Laclau y Mouffe ${ }^{6}$, debemos convenir en que aún perviven prácticasque, si bien no pueden calificarse de 'ingenuas' en términos vandijkianos, sí evidencian una predilección fragmentaria por los factores discursivos o políticos y no por la interacción dialógica de los dos sistemas de pensamiento, de tal manera que pueda darse cuenta coherente de una realidad política que sólo logrará ser entendida en tanto ontología de lo social, como lo advirtieron Laclau y Mouffe en su oportunidad (2006, p. 14).

Adicionalmente, resulta pertinente anotar que, cuando se ha emprendido la tarea de llevar a cabo el análisis de un discurso con intenciones políticas, por lo general se ha echado mano de aquellos pro-

4 Al respecto, van Dijk plantea que "no se requiere ser analista del discurso para concluir que un relato noticioso, el fragmento de un texto o una conversación determinada es 'conservadora', 'sexista' 0 'ecologista'. Nuestro conocimiento ingenuo del lenguaje, el discurso, la sociedad y las ideologías nos conducen a menudo a hacer tales inferencias con relativa certeza" (van Dijk, 1996, p. 24).

5 A manera de ejemplo de lo expuesto, el trabajo de Lope Blanch, La estructura de la cláusula en un discurso político, da cuenta de una intervención del presidente mexicano Miguel de la Madrid, caracterizada por rasgos sintácticos bastante peculiares, frente al habla cotidiana, tales como la extensión de las cláusulas, el tipo de léxico, la manera de abordar los temas, pero desaprovecha, por limitantes teóricas y metodológicas, la posibilidad de explicar aspectos claves de la significación, porque “incursiones de tal naturaleza no son propias del aprendiz de filólogo" (1987, p. 223).

6 Hegemonía y estrategia socialista. Hacia una radicalización de la democracia, Editorial Verso, Londres, 1985. En este trabajo, seguimos la $2^{a}$ edición en español, Fondo de Cultura Económica, Buenos Aires, 2006. ductos comunicativos que surgen en el ámbito de la política (partidista o gubernamental) y son escasos los análisis de otros tipos de discursos, desde esta misma perspectiva. Incluso, los estudios que se realizan con base en el marco conceptual del Análisis Crítico del Discurso (ACD) ${ }^{7}$ parecieran encontrarse más a gusto con corpus provenientes de la política que con producciones discursivas de otra índole, lo cual no les resta capacidad y contundencia interpretativas, pero -consideramos- valdría la pena ensayar otros derroteros y, de ese modo, propiciar un acercamiento cada vez más certero al interjuego de opciones teórico-metodológicas y, consecuentemente, a otras posibilidades en la conformación del orden sociopolítico en nuestro país.

\section{Acerca del Análisis Político del Discurso ${ }^{8}$ (APD)}

Recordemos que el andamiaje teórico de Laclau y Mouffe, fundamentado principalmente en el marxismo, el psicoanálisis y las ciencias del lenguaje, le proporciona a la ciencia política una nueva manera de abordar sus problemáticas con tintes posfundacionalistas y posmarxistas, como ellos mismos lo declaran, y -para el efecto- usando una metodología deconstruccionista, se proponen releer la teoría marxista iluminada por los problemas actuales de la sociedad, con el énfasis puesto en que están llevando a cabo una tarea que implica un "proceso de reapropiación de una tradición intelectual [y] de ir más allá de esta última” (Laclau y Mouffe, 2006, p. 10).

De esta manera, los autores proponen una concepción de discurso como totalidad resultante de la interrelación entre elementos que configuran un

7 Nótese que van Dijk lo caracteriza tempranamente, con pretensiones que no han sido desbordadas y que mantienen plena vigencia, en la dirección de un programa investigativo que estudia en los discursos "el modo en que el abuso del poder social, el dominio y la desigualdad son practicados, reproducidos, y ocasionalmente combatidos, por los textos y el habla en el contexto social y político. El análisis crítico del discurso, con tan peculiar investigación, toma explícitamente partido, y espera contribuir de manera efectiva a la resistencia contra la desigualdad social" (van Dijk, 1999, p. 23).

8 En bien de cierta justicia teórica, debemos aclarar que esta denominación no tiene origen en Laclau y Mouffe, sino en alguno de sus epígonos y ha ido ganando terreno entre los analistas políticos, en razón de sus alcances teóricos y metodológicos. 
sistema de significación, el cual -a su vez- determina la comprensión que los individuos han ido haciendo acerca de su desempeño en la sociedad y acerca de su propia acción política (Laclau y Mouffe, 2006, pp. 142-155). En consecuencia, el analista del discurso busca dar cuenta de las formas en que las estructuras de significación determinan "ciertas formas de conducta. Al hacer esto, pretende comprender cómo se generan los discursos que estructuran las actividades de los agentes sociales, cómo funcionan y cómo se cambian" (Howarth, 1997, p. 125), siempre en la perspectiva de la regularidad en la dispersión con la que Foucault proponía encontrar el principio unificador de su formación discursiva ${ }^{9}$.

Con análogos presupuestos, nuestros teóricos entran a revisar el tradicional concepto de ideología en los términos marxistas y lo cuestionan por su carácter regional y estrictamente superestructural, de falsa conciencia que distorsiona la verdadera naturaleza de la realidad, en función del lugar que ocupe el individuo en las relaciones de producción (Cfr. Marx, 1973, pp. 20-23), es decir, como ámbito de las ideas, en contraste con el mundo material ${ }^{10}$. Por otro lado, lamentan que no se haya dado un total desarrollo de la propuesta althusseriana de entenderla como práctica social generadora de sujetos ("toda ideología tiene como función [que la define] constituir individuos concretos en sujetos”. 1974, p. 130), plenamente entrecruzada con el accionar de los aparatos represivos del Estado.

9 En La arqueología del saber se plantean cuatro hipótesis de superación de la dispersión que, una vez puestas a prueba, se rechazan como constitutivas de un principio unificante de la formación discursiva: la referencia a un solo y mismo objeto, el recurso a un estilo similar en la enunciación, la presencia de unos conceptos permanentes y coherentes y la identidad y persistencia de los temas (Cfr., 1970, pp. 50-64).

10 Son de anotar los ecos schmittianos en la propuesta de Laclau y Mouffe, en especial con aquello de que "La filosofía marxista de la historia radicalizó e integró esta relación con la economía en un sistema al buscar un punto de atribución también para los cambios políticos y sociales, mismo que encontró en el ámbito económico. Esta explicación materialista imposibilita el análisis aislado de las consecuencias ideológicas, ya que por todas partes sólo distingue 'reflejos', 'representaciones' o 'encubrimientos' de las relaciones económicas, es decir, trabaja de manera consecuente con explicaciones psicológicas, interpretaciones y, al menos, en su versión vulgar, expresiones de recelo" (Schmitt, 2004, p. 47).
Finalmente, asumido el planteamiento de que "la conciencia no es un dato originario o un fenómeno de reflejo de una situación objetiva", (Mouffe, 1985, p. 127), se hace necesario pensar en que el agente social debe caracterizarse no sólo en función de su posición en el proceso de producción, sino, adicionalmente, por su capacidad de asumir/rechazar el papel que le es asignado por la clase dominante. De esta manera, el concepto de ideología podría asumirse como la actualización del horizonte imaginario que proporciona significación a las configuraciones discursivas, con la ostensible salvedad de que las ideologías totalitarias tienden al cierre de todos los discursos en torno a un principio único (en el plano interno) y unificador (en su manifestación externa).

El antagonismo, por su parte, es entendido como la "experiencia del límite de toda 'objetividad' [que] tiene una forma de presencia discursiva precisa" (Laclau y Mouffe, 2006, p. 164). Esta categoría se asume como diferente a los conceptos de oposición real y de contradicción, y la negación que hace de un orden determinado es el reconocimiento del límite que está imponiendo con su configuración. El APD considera fundamental la determinación de antagonismos por tres razones: i) la existencia de un antagonismo presupone la existencia de un enemigo o un otro, imprescindible para el trazado de límites; ii) el establecimiento de límites (fronteras políticas) posibilita el esclarecimiento de identidad de los discursos y de los agentes sociales; y iii) en consecuencia, la existencia de antagonismos señala paradigmáticamente la contingencia de identidades puesto que, si reconocemos que el sujeto es construcción del lenguaje que se instaura en algún orden simbólico, al cuestionar ese orden, se cuestiona asimismo la identidad.

Por su importancia para cualquier análisis contemporáneo, conviene resaltar en lo anterior las resonancias de Schmitt, para quien,

la específica distinción política a la cual es posible referir las acciones y los motivos políticos es la distinción de amigo (Freund) y enemigo (Feind) [...] Ella puede subsistir teórica y prácticamente sin que, al mismo tiempo, deban ser empleadas todas las demás distinciones morales, estéticas, económicas o de otro tipo (Schmitt, 2004, p. 177). 
La hegemonía, por su parte, constituye la categoría primordial de la teoría política del discurso, en tanto configura el ámbito en el que confluyen todas las categorías antes enunciadas. Se asume que la hegemonía sólo puede establecerse cuando existen fuerzas antagónicas y las fronteras que separan esas formaciones discursivas se tornan inestables, lo que posibilita que uno de los proyectos políticos determine las normas y significados sociales del proyecto antagónico.

Este concepto del APD, fundado en la precisión gramsciana acerca de que constituye la "dirección política, intelectual y moral”, supera la concepción leninista de alianza de clases, en tanto -con la primera- se caracteriza una clase (o más bien, una voluntad colectiva) dominante con capacidad para articular a sus ideas e intereses los de otros grupos $y$, al mismo tiempo, se le da un papel preponderante a la ideología, en su calidad de productora de sujetos de que hablara Althusser. En consonancia con lo expuesto en Los cuadernos de la cárcel,

"de esto podemos deducir la importancia del 'aspecto cultural', incluso en la actividad (colectiva) práctica. Un acto histórico sólo puede ser llevado a cabo por el 'hombre colectivo', y esto presupone el logro de una unidad 'cultural-social' a través de la cual una multiplicidad de voluntades dispersas, con objetivos heterogéneos, son soldadas en torno a un único objetivo sobre la base de una común e igual concepción del mundo (Gramsci, 1975, citado por Laclau y Mouffe, 2006, p. 102).

Para su cabal estructuración, la hegemonía requiere de la factibilidad de dos condiciones: i) que exista antagonismo con fronteras claramente diferenciadas, de tal manera que se evidencie el ejercicio de poder por parte del proyecto que busca imponerse; $y$ ii) que existan significantes flotantes (significantes vacíos) que puedan ser llenados de sentido y, por ende, articulados al nuevo proyecto hegemónico, el cual tendrá las mismas características de transitoriedad de toda práctica hegemónica, dada la existencia de antagonismos y efectos de frontera.

Con todo lo dicho, se conformará un universo de significación equiparable al imaginario político definido por Castoriadis, el cual posibilita la existencia de una forma de sociedad que se inscribe en él y que, desde él mismo, se define, desarrolla, proyecta e institucionaliza. Es necesario resaltar que este imaginario es producto, no de individuos sino de colectivos anónimos que van proporcionando elementos para llenar de sentido los significantes flotantes y al que se asigna poder que, en su vertiente explícita, "concierne a lo político [y] reposa no en la coerción -evidentemente siempre hay en mayor o menor medida coerción, la cual, sabemos, puede alcanzar formas monstruosas-, sino sobre la interiorización por los individuos socialmente construidos, de las significaciones instituidas por la sociedad" (Castoriadis, 1997, p. 196).

\section{Algunas consideraciones acerca de la política}

Tradicionalmente asistimos a la manifestación de un imaginario que pervive a pesar de los embates de múltiples esquemas ideológicos: la acción política no tiene (no puede tener) un fundamento en valores que constituyan una organización ética, pues como lo vimos con Schmitt, la política tan solo tiene sentido en tanto exista la posibilidad de reagrupar las comunidades en términos de amigo-enemigo, en una unidad de rango mayor a lo simplemente asociativo-social, en tanto lo que importa siempre es sólo lo concerniente al conflicto ${ }^{11}$, lo cual es reafirmado por Croce cuando observa que la guerra constituye la más alta y evidente manifestación de la conflictividad humana, si bien siempre se corre el riesgo de que aparezca algún haragán que

esté dispuesto a reemplazarla por cualquier cosa que, aunque carente de sentido, tenga a la vez el sentido de negar la lucha y acariciar con palabras el ideal de la pereza: la justicia social e internacional, la igualdad, la fraternidad, la armonía entre las clases, la unión de los pueblos (Croce, 1952, p. 149).

11 “La guerra no es un fin o una meta, o tan solo el contenido de la política, sino que es su presupuesto siempre presente como posibilidad real y que determina de modo particular el pensamiento y la acción del hombre, provocando así un comportamiento político específico" (Schmitt, 2004, p. 184). 
Por ello, nada más consecuente con esta posición que asignarle el carácter de imbecilidad y de petulancia alejada de todo esfuerzo racional, al hecho de esperar que pueda haber algún tipo de valores en la acción política, tal como lo expone con suficiencia en su ensayo La honestidad política.

Incluso, es necesario citar a un amplio sector de teóricos, a los que denominan neoschmittianos de izquierda, que continúan haciendo eco de estos planteamientos y cerrándole el paso a opciones dialogadas, dialógicas o dialogantes, para no mencionar a los legítimos herederos de quien fuera ideólogo del régimen nazi ${ }^{12}$.

Para no ir más lejos, pensamos en los mismos Laclau y Mouffe quienes, en diversos textos, se han referido a esta problemática, aunque es justo decirlo, últimamente con algunos matices: "Una visión idealizada de la sociabilidad humana [en la que] la violencia y la hostilidad son percibidos como un fenómeno arcaico, a ser eliminado por el progreso del intercambio y el establecimiento, mediante un contrato social, de una comunicación transparente entre participantes racionales" (Mouffe, 2007, p. 100), con lo que se refrendan estas palabras de 2002, motivadas por el modelo de democracia deliberativa de Habermas y otros: "Para nosotros, una esfera pública, sin exclusiones y dominada enteramente por la argumentación racional, es una imposibilidad conceptual" (Laclau y Mouffe, 2006, p. 18) y "sin antagonismo no habría ninguna posibilidad de democracia radical. Para que haya antagonismo tiene que haber un enfrentamiento con un poder que obstaculiza. El antagonismo es central en la constitución de un imaginario de cambio" (Laclau, en Keve, 2010).

\footnotetext{
12 Es de anotar que existen quienes, o se dan a la tarea de negar la adscripción de Schmitt al nacionalsocialismo y su intento de convertirse en el ideólogo, primero del movimiento, entre otras cosas, por el reconocimiento académico de que gozaba, o privilegian el distanciamiento y subsecuente recelo del partido hacia Schmitt, luego de la carnicería de Stalingrado. No obstante, en aras del equilibrio teórico, es indispensable reconocer que el intelectual alemán representa, para las ideas políticas, mucho más de lo que su relación y distanciamiento con el nazismo le han aportado para ser considerado un hegeliano ignominioso (Cfr. Jean-François Kervégan, 2007).
}

Ahora bien, el mismo Laclau ha referido su cercanía conceptual a una ética del compromiso militante $^{13}$ que i) está articulada con un proyecto emancipador y -como en el caso de Alain Badiouse aleja de las intentonas defensivas y asume un discurso plenamente afirmativo; ii) se hace universal, en tanto vinculada con acontecimientos concretos y situados; y iii) no se despliega en un conjunto de normas morales de aplicación indistinta y general.

Frente a lo expuesto, se vislumbran dos posibilidades de acción:

La primera, asumir la política en su dimensión de disociación, mediante la cual se la ve como una amenaza permanente, en la que no se privilegian ficciones, normas ni posturas éticas o estéticas: lo que tiene importancia es la guerra, la supervivencia. Se trata de una conceptualización de la totalidad de lo político y el desliz hacia un Estado total que no reconoce nada que no sea político, con el absoluto desconocimiento de los individuos, excepto en su adscripción a los términos de la específica diferencia schmittiana y, ante todo, la potencial inexistencia en un ámbito delimitado (está en todos) pues lo único que indica es el grado de intensidad de la asociación o la disociación que ha sido determinada. De esta manera resulta posible, igualmente, que la política se abstraiga de cualquier injerencia de valores o cualidades puramente espirituales y que se mantenga lejos de la influencia de la humanidad, por cuanto ésta carece de enemigos y, en consecuencia, ella no puede iniciar ninguna guerra; ahora, que cometer la indelicadeza de asociar la humanidad con lo político puede ir en la dirección de desconocer el carácter humano del enemigo. Y, claro, tampoco se pretenderá el recurso a la ética, en tanto, ¿de qué valores puede hacer gala un hombre al que "todas las teorías políticas en sentido estricto suponen como 'malo', o sea que lo consideran un ser extremadamente problemático, más bien 'peligroso' y dinámico"? (Schmitt, 2004, p. 207).

La segunda es la de asumir la política como escenario para la asociación, tal como nos lo propone Arendt, escenario éste en el que el ser humano

13 Cfr. Laclau, Debates y combates, 2008: 67-106. 
alcanza su realización como tal, en otras palabras, se trata de una actividad esperanzadora, que no amenaza, no divide, no busca la eliminación física del adversario y, por el contrario, fundada en los aportes de la acción $n^{14}$ y el discurso puede constituirse en promesa de restauración de la unidad dialógica del hombre con sus semejantes y con el mundo, a través del pensamiento en libertad.

De todas maneras, aquí cabe una digresión: la relación discurso-acción, fundamento de la política -dadas las limitaciones que Arendt ve en la acción (no-predicción de sus consecuencias e irreversibilidad de las acciones mismas)- nos pone ante el riesgo de que la palabra se distancie tanto de la acción, que no pueda ser garante de la pluralidad ni de la posibilidad de vivir juntos, aspectos básicos del accionar político. De igual manera, otra situación podría advertirse cuando -a sabiendas de lo impredecible e irreversible que es la acción- el sujeto actúa irresponsablemente tanto sobre lo que le compete a su supervivencia y a la supervivencia del mundo, como a la propia realización de la vida política en la que obligatoriamente se afectan los otros, con los cuales se teje el entramado de la vida misma, a pesar de "la 'oscuridad del corazón humano', o sea, de la básica desconfianza de los hombres que nunca pueden garantizar hoy quiénes serán mañana" (Arendt, 2002, p. 263).

\section{Los avatares de una política pública}

Partamos de anotar que Laclau determina como unidad mínima de análisis ${ }^{15}$ la demanda social, en su doble acepción de petición y reclamo que, con alguna licencia, podemos asumir como elemento que estaría en la génesis de la problematización

14 Nótense aquí algunas diferencias entre la concepción de acción política por parte de Croce "lucha de partidos, imposiciones de leyes que son la victoria para algunos y la derrota para otros, convenios diplomáticos, tratados de comercio, guerras de tarifas, guerras de armas" (1952, p. 149) y por parte de Arendt, para quien este concepto es el de más alta jerarquía en la vita activa y, junto con el discurso, permite que los hombres se diferencien en lugar de ser sólo distintos, hecho que "no ocurre en ninguna otra actividad de la vita activa" (Arendt, 2002, p. 200).

15 Lo hace en su trabajo sobre el populismo, en cual se da a la tarea de sacarlo de la posición marginal que las ciencias sociales y políticas le han asignado. Cfr. La razón populista, 2006. de la sociedad con miras a la formulación de una agenda gubernativa determinada. De todas maneras, es innegable que una buena cantidad de demandas (en el sentido de peticiones, no necesariamente explícitas) que no han sido satisfechas, pueden generar un caldo de cultivo eficaz para el malestar social y la deslegitimación de un determinado proyecto político, adquiriendo la demanda -con ello- el sentido de reclamo, y petición y reclamo, con nuevos significados y contextos ideológicos, auspiciarán la irrupción de otro proyecto hegemónico; en caso contrario, resultarán aportándole a la consolidación de un universo simbólico favorable que se sustenta en las realizaciones, ejecutorias y conductas de los gobernantes.

Y es aquí, en la acción de gobierno, donde -de acuerdo con Medellín- se encuentran en un único referente los procesos de diseño, implementación y evaluación de políticas públicas, con lo que se enriquece la relación Estado-sociedad, se garantiza una cierta efectividad de las políticas y se precisa la manera de dar respuesta a las demandas que surgen en el ámbito privilegiado de esa relación. Y este innegable aporte del autor: el objeto de estudio de las políticas estaría dado no tanto por la gestión administrativa del Estado (el cuerpo especializado), ni por la racionalidad o la adecuada implementación de las políticas, como por "indagar los problemas que se le presentan al gobernante en la conversión de sus ideas en acciones de gobierno" (Medellín, 2006, p. 139).

Entre las particularidades que caracterizan la estructuración de las políticas públicas en regímenes de obediencias endebles ${ }^{16}$ es necesario asumir la complejidad de los procesos, la coexistencia de agentes, agencias y discursos que evidencian la contingencia de su evolución, la lucha por el poder de un territorio o de un ámbito del Estado, y una institucionalidad tan frágil en la que "la existencia de tensiones y conflictos no sólo limita la movilidad de los recursos disponibles, sino [que] también su-

16 Es Medellín (2006) quien da vía a esta denominación. Sin embargo, con el ánimo de propiciar una mayor claridad, atiéndase lo expuesto en la nota 17 de este mismo trabajo. 
bordina la consistencia y continuidad de las políticas públicas a los quiebres de la coyuntura política" (2006, p. 121).

Ahora bien, es innegable que las condiciones de la década de los años 90 del siglo XX fueron ricas en demandas sociales de índole diversa y, en el caso que nos interesa para estas páginas, una vez canalizadas, fue posible la promulgación de la Constitución Política de 1991 y, posteriormente, el diseño y formulación de la Ley 115 de 1994 o Ley General de Educación, con la cual nuestro país pareció ponerse a tono con las legislaciones de otros países latinoamericanos y pensarse en función de lo que su sociedad quería para la formación de las nuevas generaciones de colombianos, todo ello liderado por los debates, las propuestas y las movilizaciones que los maestros del país venían haciendo desde décadas anteriores a través de la Federación Colombiana de Educadores y, a partir de 1982, con el Movimiento Pedagógico, lo cual es sintetizado, poniendo el énfasis en la conciencia política de los agentes sociales, de la siguiente manera:

Cuando el proceso constituyente de 1991 se desencadena, el acumulado de esfuerzos desplegados desde el Movimiento Pedagógico produce lo que Bourdie[u] llamó la magia social. En ese momento, rectores de universidades, artistas, investigadores, profesionales, empresarios, rectores de colegios privados, profesores universitarios, de secundaria y de primaria, elaboraron un conjunto de propuestas que enriquecieron de un modo sorprendente el debate sobre la cuestión educativa en la constituyente. En el seno de la constituyente dos ex presidentes de Fecode: Germán Toro y Abel Rodríguez, expresaron la conciencia política de los maestros. Fue así como se produjo un cambio radical en el constitucionalismo colombiano. (Arcila Ramírez, 2002, p. 13).

Como es de uso en las políticas públicas, sólo con posterioridad se inicia el proceso de reglamentación de la ley, la cual empieza a coincidir con una aparente disminución de la participación de los maestros en su definición y, al mismo tiempo, con un proceso de deslegitimación del Estado que, al decir de algunos autores, surge de dos fuentes de inesta- bilidad que se hacen evidentes "en la cada vez más extendida influencia de las redes del narcotráfico y su infiltración en las instituciones claves de la sociedad [...y...] en el crecimiento de los ejércitos de la guerrilla, los paramilitares y las fuerzas de seguridad 'privadas"' (Rabasa y Chalk, 2003, p. 181).

Transcurren siete años de discusiones y debates, en los que la fuerza ganada por el gremio de maestros aglutinado en Fecode, parece perder el protagonismo alcanzado en 1994 en la construcción de la política educativa, fuerza que se ve severamente disminuida con la aprobación del Acto Legislativo 001 de 2001 y la Ley 715 del mismo año que, muy a pesar de la oposición de los maestros y de lo que implicaba en el empobrecimiento de los logros alcanzados en el 94 para la educación colombiana, fue aprobada en el Congreso y continúa vigente hasta el día de hoy, ampliado en sus límites a través del Acto Legislativo 011 de 2006, todo lo cual representa para la educación un mayor recorte en su financiación por parte del Estado.

El Movimiento Pedagógico, por su parte, empieza a difuminarse $y$, para algunos, a transformarse en otras formas de resistencia: grupos como la Movilización por la Educación Social o proyectos como la Expedición Pedagógica se asumen en su calidad de mecanismos que prolongan, de alguna manera, las formas de movilización alcanzadas por el Movimiento Pedagógico pero que, en sí mismas, no lo constituyen (Cfr. Mejía, 2006, Cap. 5) ni logran reemplazarlo.

Recordemos que en la década de los años 90 hace crisis un país golpeado por la violencia del narcotráfico, con sus líderes políticos asesinados, con una guerra no declarada, en uno de cuyos bandos comenzaron a confluir diferentes sectores alrededor de una voluntad colectiva que fue haciéndose más fuerte a medida que iba obteniendo logros militares, incluido el exterminio -iniciado desde la década anterior- de todo un movimiento político de izquierda. Todo esto en juego con una tendencia económica que implicó la adscripción al orden neoliberal global, la "pérdida de la confianza inversionista" a partir de la descertificación norteamericana a la lucha contra las drogas y la recesión 
económica que concluyó, en el segundo trimestre de 1999, con un acrecentamiento de la contracción económica y del desempleo, con una consecuente disminución del $\mathrm{PIB}^{17}$. No obstante, el imaginario político hegemónico correspondía al de quienes habían concitado la voluntad de pensar un nuevo país y ofrecer alternativas políticas con énfasis en lo social. Lamentablemente, este imaginario fue diluyéndose en los altares de la confrontación armada y la economía criminal subterránea de que hablan Rabasa y Chalk. Ese país en crisis quedó ad portas de convertirse en lo que Helman y Ratner denominaron Estado fallido. ${ }^{18}$

Con estos hitos contextuales, debemos indagarnos acerca de lo ocurrido con las motivaciones de la Ley 115 y de la manera como se fue perfilando un nuevo discurso que tomó significantes flotantes tales como seguridad, violencia, paz, democracia, entre otros, y los llenó de nuevos contenidos para ponerlos a gravitar en el universo de su lógica amigo/enemigo, entendido éste último como todo aquel que no compartiera los presupuestos de los nuevos señores de la guerra que terminaron por hacerse, también, al poder político, tal como lo ha venido determinando la justicia colombiana en los últimos años.

Mientras se hacían evidentes unas pretensiones de tipo democrático, altamente participativas y reivindicativas, como las que animaron la defi-

17 El cual, al decir del Wall Street Journal del 23 de septiembre de 1999, fue proyectado en un 3,5\% anual para ese año (Citado por Rabasa y Chalk, op. cit.).

18 Diferentes autores se han ocupado de las dificultades que evidencian nuestros Estados para dar respuesta a las demandas sociales, así sea sólo haciendo uso de unas políticas públicas de carácter simbólico, cuya esencia no consiste en ofrecer alternativas viables a problemas del país, sino en "el decir, el hacer saber y hacer creer que se actúa o que se preocupa por intervenir", tal como lo han expuesto con suficiencia Cansino (1993) y Edelman (2002). Con el ánimo de acercarse a la dilucidación de este aspecto, se han propuesto algunas denominaciones (ya sea desde el régimen político, desde el gobierno o desde el Estado), entre las que cabe mencionar: sociedades de suma cero (Lester, 1980), democracias inciertas (O'Donnell y Schmitter, 1991), Estados fallidos (Helman y Ratner, 1992), Estados colapsados (Zartman, 1995), Estados desestructurados (Thürer, 1999), el ya clásico de sociedades menos favorecidas (Rawls, 2001), obediencias endebles (Medellín, 2006) y Estados en crisis (Fernández, 2009), los cuales -aunque no sean estrictamente equivalentes- sí dan cuenta desde perspectivas complementarias de la incapacidad (relativa o absoluta) para ejercer las funciones primarias de protección de los ciudadanos. nición de la Ley $115^{19}$, se fue conformando otro imaginario, fundado en la violencia, la exclusión y el desconocimiento de los derechos de las minorías políticas, sin que pudiera oponerse algún contrapeso a partir, precisamente, de la implementación de toda la riqueza ideológica que subyace a la misma Ley, la cual configura un camino que, desde el aspecto cultural gramsciano puede potenciar la constitución de individuos en sujetos, tal como ha sido expuesto anteriormente. Quedarán por verse, mediante otros acercamientos analíticos, las maneras en que un proyecto hegemónico (el que da pie a la Constitución Política de 1991 y la Ley 115 de 1994) se desdibuja y permite, en un contexto como el antes explicitado, la irrupción de otro proyecto que, al igual que todos, se fundamenta en los pilares de la contingencia y la transitoriedad mientras busca llenar de sentido unos significantes flotantes (vacíos) que, de alguna manera, están emparentados con las demandas sociales, sean explícitas o no, tal como se verá un poco más en detalle en el siguiente apartado.

\section{Un imaginario político hegemónico}

Hace ya más de un año se difundió una noticia relacionada con la visita que realizó el entonces presidente de la república a la capital del Vichada, donde quedó en evidencia que había sido contagiado con el virus de la influenza AH1N1, conocido hasta algunos días antes como gripa porcina.

Para efectos del cometido de esta parte del trabajo, recordemos que -en agosto de 2009-el noticiero Caracol transmitió un reporte desde Puerto Carreño, en el que daba cuenta de la situación en que estaba el municipio luego del Consejo Comunitario realizado allí. Lo que es de resaltar para el análisis no es la noticia misma, sino la peculiar manifestación de una ciudadana, con respecto a la enfermedad presidencial:

19 Piénsese en los significantes flotantes movilizados por la Ley 115 , entre los cuales sobresalen los de autonomía, construcción de sujeto, cultura nacional, diversidad étnica, comunidad educativa, educación como derecho, etc. 


\section{Periodista:}

Mucha gente en las calles conoce la anécdota del presidente, pero no conoce muy bien de qué se trata la enfermedad.

\section{Entrevistada:}

Esto... Nosotros, cada quien, podemos tener una gripa normal... ¿cierto?... Pues realmente... yo no sabía que verdaderamente el señor presidente tenía VIH, pero cada metabolismo reaccionamos diferente, tenemos nuestras autodefensas... Mi organismo está bien...

Todo lo que ha ocurrido aquí -nos podría decir un psicólogo, un psiquiatra o un psicoanalista- fue la expresión de un acto fallido en que puede incurrir cualquiera de nosotros por múltiples razones: fatiga, descuido, desinterés, estrés, etc. Y tendrán razón: se trata de una de las cuatro operaciones fallidas que menciona Freud ${ }^{20}$, la correspondiente al lapsus verbal, mediante el cual un hablante verbaliza un contenido diferente y, en ocasiones, contrario a lo que quería decir. Hasta aquí, nada que se salga de la normalidad.

Ahora bien, teniendo claridad acerca de que ningún significante resulta gratuito en la posibilidad de análisis, en la medida en que conlleva un sentido que se actualiza en su relación con otros y que siempre existirá contigüidad vinculante entre lo dicho y lo callado, dentro de un discurso específico (con la lógica ausencia/presencia de que diera cuenta Derrida), surge la intuición de encontrarnos frente a un elemento significativo que, al ponerse en consonancia con otros que circulan en el ámbito de los imaginarios políticos del país, puede adquirir una categoría diferente, en discurso diferente. En este caso, se trata del discurso que ha sido el hegemónico en los últimos ocho años de la historia nacional.

Nos referimos a un discurso en el que -con base en el más ortodoxo Schmitt- fueron delimitadas

20 Cfr. Psicopatología de la vida cotidiana. claramente las fronteras, definido el enemigo -tanto interno como externo- y especificados los puntos de articulación de quienes podrían conformar la coalición de los amigos ${ }^{21}$. Y allí fueron plenamente colmados significantes móviles como los de la seguridad y la democracia, por ejemplo, que propiciaron el diseño, implementación y evaluación de una política pública que terminó siendo elevada a la categoría de política de estado y que, en el arrobo máximo del testamento político, se incluyó dentro de los tres huevitos que el presidente anterior legó a su sucesor, con el encarecido ruego de cuidarlos y lograr que fuesen empollados. En el mismo ámbito, piénsese en otra política pública emparentada con estos significantes (Agro Ingreso Seguro) y en la conceptualización de una democracia comunitaria que se hizo evidente en los Consejos Comunales de Gobierno, durante los cuales siempre se vio quién era el mandatario y quiénes los mandados, al mejor estilo de lo que Edelman caracteriza en su espectáculo político: "el lenguaje que genera y refuerza las creencias sobre quiénes son los aliados y quiénes los enemigos constituye un caso especialmente sorprendente de la proyección de supuestos divergentes en palabras y oraciones" (Edelman, 2002, p. 123), a un punto tal que se sucedían regaños públicos a funcionarios del gobierno, reclamos, órdenes directas, etc., los que eran recibidos por la audiencia como si fuesen portadores de innegables condiciones taumatúrgicas.

Otro significante flotante que terminó recibiendo la más alta carga de desprestigio fue el de los partidos políticos $^{22}$, con el riesgo de desinstitucionalización del Congreso, por ejemplo, y el consecuente engrandeci-

21 Diferentes investigadores y analistas han mostrado cómo se conformaban tales coaliciones y cómo, a pesar de las denuncias y cuestionamientos de múltiples procedencias, se mantuvieron en aras de suplir las necesidades de pervivencia del régimen.

22 Al respecto, Cfr. el valioso trabajo de F. Gutiérrez Sanín (2007), donde, apartándose de las interpretaciones corrientes, lleva a cabo una agudísima revisión de las especificidades, acciones y ejecutorias de nuestros partidos políticos. Ahora bien, si el debilitamiento de los partidos tradicionales puede rastrearse en todo el mundo, es innegable que en Colombia el ejercicio del poder en términos schmittianos y el uso de estrategias politiqueras sumadas a la crítica de la politiquería misma por parte del entonces presidente, influyeron en el desprestigio de los partidos y en su ostensible debilitamiento en términos electorales, sociales y culturales. 
miento del líder en cuya cabeza cabían el país y todos sus habitantes. Por aquello del valor de una imagen, veamos esta valla publicitaria ubicada en Bogotá en la época previa a las elecciones parlamentarias de 2010, en la que supervivieron los fantasmas del narcotráfico, la parapolítica y el intento de ser electo, no importando los medios o las estrategias utilizadas para el efecto:

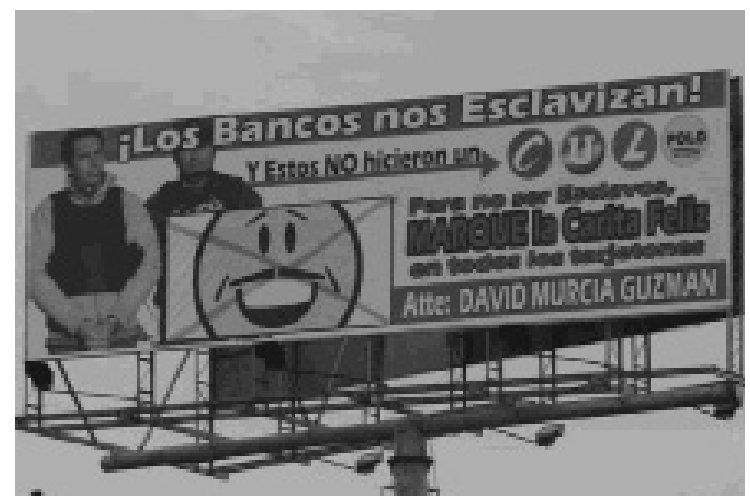

Esta utilización del discurso electoral con pretensiones descalificadoras, tuvo también su génesis, i) no sólo en la fatiga de los electores frente a un sistema "democrático" que únicamente busca serlo en cuanto a la realización de elecciones, en el que ha primado el concepto de seguridad sobre el de fraternidad, y la libertad por la que ha abogado va en la dirección totalitaria del mercado, sino ii) asimismo, en la postura ideológica del primer mandatario con respecto a los integrantes de un grupo social que se resistía a continuar siendo subordinado de quien ejercía el poder, es decir, en términos schmittianos, de quien tenía la capacidad de decisión. No nos referimos aquí a los contradictores y opositores del entonces presidente, quienes engrosaron sin más el espectro del enemigo interno con "claros" nexos con el enemigo externo, uno y otro agrupados bajo el significante flotante de terroristas; aquí hacemos alusión a cierto sector de la élite que actuó de consuno con el líder máximo, para quien sus integrantes representaban, a lo sumo, un grupo de petimetres pomposos que interactuaban en los clubes sociales de Bogotá, dejando los destinos del país en manos de los violentos (de un sector de violentos, sería mejor decir, aquel que hacía parte del enemigo, pues el sector violento articulado al proyecto hege- mónico quedaba por fuera de esta caracterización, entre otras cosas porque ellos también asistían a los clubes sociales y a los lugares de moda en diferentes regiones del país y recibían el reconocimiento de sus calidades político-militares) ${ }^{23}$. Irónicamente, y como resultado de una justicia de élites, el líderhegemón debe soportar una descripción descarnada como ésta:

a lo mejor esta forma de ser, tan ajena a los rituales burgueses, ha sido la culpable de que en Medellín la oligarquía paisa lo considere un 'presidente montañero', calificativo que, escuchado desde los salones del selecto Club Unión de Medellín, no deja de sonar un tanto clasista (Duzán, 2004, p. 21).

De igual manera, se generó toda una corriente de opinión en contra de la guerrilla y de apoyo a los secuestrados, entre los cuales también se evidenció cierto discurso hegemónico. Esto es palpable, sin ir más lejos, en la reacción de una representante de la élite política, la excandidata Ingrid Betancourt, quien durante su cautiverio y ante una serpiente de más de ocho metros de largo que fue capturada y puesta como espectáculo ejemplarizante, óptimo para el escarmiento de los rehenes que pretendieran escapar, al señalarles con elementos ostensibles los peligros de la selva, manifiesta en sus memorias que "los guerrilleros lo llamaban güío (sic) en tanto que

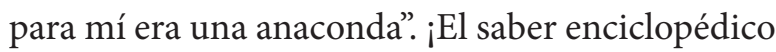
con pretensiones hegemónicas, ante todo!

Con estos mínimos elementos, en juego dialógico con las palabras de la entrevistada de Puerto Carreño, resulta evidente que su lapsus se inscribe en el ámbito privilegiado de un imaginario que sustenta un discurso hegemónico, en el que todos los significantes aludidos adquieren sentido y nos hablan de un específico período histórico y político de nuestro país, signado por el odio abierto y declarado a determinados sectores violentos, la analogización de éstos con toda fuerza (colectiva o individual) de

23 Aparte de las noticias de prensa de la época, Cfr. A las puertas del Ubérrimo (2008) y Así gobierna Uribe (2004), entre muchos otros documentos que aclaran cuál es la visión que el exmandatario tiene (¿tenía?) de sus aliados. 
oposición; la presencia implícita de cierta connivencia con otros sectores violentos, así como la llegada de éstos últimos a las más altas esferas de la política nacional, sin que haya podido plantearse solución a los males endémicos de nuestra sociedad.

\section{Palabras finales}

Esta rápida panorámica de la teoría del Análisis Político del Discurso y su más abreviada concreción en un par de casos, nos permiten entrever algunas de las bondades de la propuesta, así como varias de las dificultades que pueden sobrevenir con su uso. Sin embargo, lo cierto es que proporciona herramientas analíticas y metodológicas que pueden ser de enorme utilidad para entender el ahora, desde la perspectiva de la significación política, y asumir si está constituido por la amenaza de la permanente disociación y exclusión o por la certeza esperanzadora de que todo está por hacerse, en tanto nada nos ha sido regalado como nos lo recuerda el bellísimo aforismo de René Char con que Arendt inicia su libro Between Past and Future: "Nuestra herencia no está precedida por testamento alguno" (Arendt, 1961, p. 3).

Tal vez este camino nos permita abordar-deslindados de las pretensiones del APD ortodoxo- una

\section{Bibliografía}

Althousser, L. (1974). Ideología y aparatos ideológicos del estado. En La filosofía como arma de la revolución. México: Cuadernos de Pasado y Presente.

Arcila, G. (2002). Prólogo. En La educación después de la Constitución del 91. De la reforma a la contrarreforma. Bogotá: Cooperativa Editorial Magisterio - Corporación Tercer Milenio.

Arendt, H. (1961). Between Past and Future. Six Exercises in Political Thought. New York: The Viking Press.

Arendt, H. (2002). La condición humana. Barcelona: Paidós. reflexión sobre los riesgos del totalitarismo y de la libertad, así como las implicaciones de la política como ámbito de realización humana que requiere de las condiciones propias de la acción, el pensamiento y la contemplación, siempre desde la perspectiva de un discurso que se constituye como hegemónico en la medida en que corresponde al imaginario político que ha logrado imponerse sobre otro(s) que, a pesar de todo, continuará(n) en su conflicto, el cual podrá ser develado y debelado a través del debate argumentado de ideas, pues aquí no se trata simplemente de tomar partido: de lo que se trata es de propiciar la clarificación de los contextos en los que se generan los discursos en la organización social, la manera como se hegemonizan y, con ello, detectar alternativas de llenado de los significantes móviles que campean por nuestro discurso cotidiano y pueden constituir discursos alternativos para la construcción de nuevas formas de poder.

Por último, es posible que un abordaje de este tipo propicie un diálogo franco y productivo entre los saberes de las Ciencias del Lenguaje y de la Ciencia Política y, con ello, la complejidad de los procesos comunicativos -abordados desde la perspectiva de la acción política- podrá tener, asimismo, una explicación mucho más compleja y coherente con las expectativas de las disciplinas involucradas.기

Betancourt, I. (2010). No hay silencio que no termine (Frag.). En revista Semana (No. 1481), 24-30.

Castoriadis, C. (1997). Imaginario político griego y moderno. En El avance de la insignificancia. Buenos Aires: Eudeba.

Cepeda, I. y Rojas, J. (2008). A las puertas del Ubérrimo. Bogotá: Debate.

Croce, B. (1952). La náusea por la política. En Ética y política. Seguidas de la contribución de la crítica de mí mismo. Buenos Aires: Ediciones Imán.

Duzán, M. (2004). Así gobierna Uribe. Bogotá: Editorial Planeta. 
Edelman, M. (2002). La construcción del espectáculo político. Buenos Aires: Ediciones Manantial.

Foucault, M. (1970). La arqueología del saber. México: Siglo XXI Editores.

Freud, S. (1999). Psicopatología de la vida cotidiana. Madrid: Alianza Editorial.

Gutiérrez Sanín, F. (2007) ¿Lo que el viento se llevó? Los partidos políticos y la democracia en Colombia (19582002). Bogotá: Grupo Editorial Norma.

Howarth, D. (1997). La teoría del discurso. En D. Marsh y G. Stoker (Eds.), Teoría y métodos de la ciencia política. Madrid: Alianza Editorial.

Keve, C. (2010). Ernesto Laclau: 'Sin antagonismo no hay democracia.. Entrevista (29 de junio de 2010). En Portal Iade / Realidad Económica. http://www.iade. org.ar/modules/noticias/article.php?storyid=3111. Recuperado el 30 de agosto de 2010.

Kervégan, J. (2007). Hegel, Karl Schmitt. Lo político: entre especulación y positividad. Madrid: Escolar y Mayo.

Laclau, E. (2006). La razón populista. México: Fondo de Cultura Económica.

(2008). Una ética del compromiso militante. En Debates y combates. Por un nuevo horizonte de la política. Buenos Aires: Fondo de Cultura Económica.

Laclau, E. y Mouffe, C. (2006). Hegemonía y estrategia socialista. Hacia una radicalización de la democracia. Buenos Aires: Fondo de Cultura Económica.

Lope, J. (1987). La estructura de la cláusula en un discurso político. En Análisis gramatical del discurso. México: UNAM. $2^{\text {a }}$ edición.

Marx, C. (1973). La ideología alemana. En Obras escogidas I, Cap. I. Moscú: Editorial Progreso.
Medellín, P. (2006). La política y las políticas públicas en regímenes de 'obediencias endebles'. Una propuesta para abordar las políticas públicas en América Latina. En R. Franco y J. Lanzaro (Coords.), Política y políticas públicas en los procesos de reforma en América Latina. Madrid: Cepal, Flacso, Ministère des Affaires Étrangères \& Miño y Dávila Editores.

Mejía, M. (2006). Educación(es) en la(s) globalización(es). Entre el pensamiento único y la nueva crítica. Bogotá: Ediciones desde abajo.

Mouffe, C. (1985). Hegemonía, política e ideología. En J. Labastida (Coord.), Hegemonía y alternativas politicas en América Latina. México: Siglo XXI Editores.

Mouffe, C. (2007). En torno a lo político. Buenos Aires: Fondo de Cultura Económica.

Rabasa, A. y Chalk, P. (2003). El laberinto colombiano. La sinergia entre drogas e insurgencia y sus implicaciones para la estabilidad regional. En El laberinto colombiano: propuestas para la resolución del conflicto. Bogotá: Universidad Externado de Colombia.

Schmitt, C. (2004). Carl Schmitt, teólogo de la política. México: Fondo de Cultura Económica. Prólogo y selección de textos: Héctor Orestes Aguilar.

Van Dijk, T. (1996). Análisis del discurso ideológico. En Discursos.org. http://www.discursos.org/oldarticles/ An\%E1lisis\%20del\%20discurso\%20ideol\%F3gico. pdf. Recuperado el 15 de agosto de 2010.

(1999). El análisis crítico del discurso. En Discursos.org. http://www.discursos.org/oldarticles/ El\%20an\%E1lisis\%20cr\%EDtico\%20del\%20discurso.pdf. Recuperado el 15 de Agosto de 2010. 